\title{
Temporomandibular disorders and benefits of a cervical therapeutic approach in facial myalgia treatment: A review of the literature
}

\author{
Maxine Aguila ${ }^{1}$, Mathieu Benichou ${ }^{2}$, Antonin Hennequin ${ }^{2}$, Geneviève Grégoire ${ }^{3}$ and Florent Destruhaut ${ }^{2 *}$ \\ ${ }^{1}$ Rangueil Hospital, Toulouse, France \\ ${ }^{2}$ Faculty of Odontology, University Toulouse III, France \\ ${ }^{3}$ Faculty of Odontology, University Toulouse III and University Paris Descartes, France
}

\begin{abstract}
Objectives: The aim of our study is to point out the link between myofacial pain and cervical rachis in temporomandibular disorder (TMD) cases.

Methods and materials: The research is conducted on Pedro, PubMed and Cochrane. The studies included must be of subjects having myogenic TMD and must concern pain parameters and /or temporomandibular cinematic.

Results: 11 articles published between 2010 and 2016 were selected (after sorting through 791 studies). 8 of them are cross sectional cohort studies and the other 3 are randomized comparative studies. The subjects show an enhancement of the extra-trigeminal pain, an increase of the angle Eye-Tragus-Horizontal, and a weakness of the cervical extensors.

Conclusion: This subject shows a sub-occipital hyper-extension and forward head posture spread heading pressure on the manducator muscles. The muscles must be balanced between the cranio-cervical position and the hyoid bone anchoring. An excessive nociceptive stimulation can lead to a remodeling of the cortical pain system. Complementary studies need to be lead to highlight the effects of postural and global physiotherapy techniques.
\end{abstract}

\section{Introduction}

Temporomandibular disorders affects 5 to $12 \%$ of the population with a female prevalence [1]. It is possible to show a great variability in terms of prevalence because it depends on the criteria taken into account to define the disorder. The 1992 Research Diagnosis Criteria for Temporomandibular Disorders (RDC/ TMD) defines different TMD types such as muscular, discal and degenerative troubles [1,2]. Muscular disorders can induce pain beyond the anatomical limits of the muscles used in themselves and also have a distant ripple effect on the body.

Reffered pain is one of the three categories defined by RDC/TMD, including myofacial pain and local myalgia. Updated diagnostic criteria in 2014 included all this myalgias in four muscular pain subtypes: myalgias, tendinitis, myositis and spasms [3]. Wiesinger highlighted a relation between frequency and rachis pain toughness and TMD diagnosis, underlighting a strong co-morbidity [4]. It seems that manual therapy applied to rachis is efficient enough in facial myalgias treatment [5]. The therapy efficiency shows a cervico-mandibular entanglement.

The aim of this literature review is to look for physiopathological links between myofacial pain and cervical rachis in temporomandibular disorders. This research could bring additional elements concerning mandibular myalgia care.

\section{Methods and materials}

\section{Methods and articles research}

The research method is based on PRISMA recommendations [6]. Research lead on Pubmed, Cochrane and Pedro are made with combined keywords such as («temporomandibular disorders» OR «masticatory muscle») AND («physiotherapy» OR «cervical» OR «cervical pain» OR «neck pain»). Only the last ten years of study are taken into account in the research. The last article was researched on March 15, 2018.

\section{Lecturing Method and article selection}

The article selection is made by reading titles, abstracts and finally a complete reading. A proof reading of synthesized elements is then made by Dr Hennequin, senior lecturer and Dr Destruhaut, Professor Associate.

*Correspondence to: Florent Destruhaut, Faculté de Chirurgie Dentaire, 3 chemin des Maraichers 31400, TOULOUSE, France, Tel: +33 (0)6 7483 34 59; E-mail: destruhautflorent@yahoo.fr

Key words: temporomandibular disorders, facial pain, maxillo-facial kinesitherapy, cervical treatment

Received: July 01, 2019; Accepted: July 17, 2019; Published: July 22, 2019 


\section{Inclusion criteria}

We selected studies including patients over 18 years old, having muscular induced TMD with or without cervicalgia. We excluded studies of patients under 18 years of age who didn't have TMD or who only had one TMD of non muscular origin. People having the following troubles were also excluded: past history of rachis trauma or face trauma, past history of rachis surgery or rachis or maxillafacial bone malformation, systemic pathologies such as fybromyalgia or inflammatory rheumatisms, neurological alteration like trigemini nerve nevralgia, and cervical discopathy.

\section{Intervention and comparison}

This literature review concerns studies that evaluated the application of physical therapy technics on temporomandibular articulation or cervical rachis with the aim of treating myogenic TMD. This review also takes into account studies comparing the differences between patient with TMD and healthy patient in terms of morphostatic, kinematics, neurological and muscular parameters.

\section{Assessment criteria}

We include articles that evaluate:

- Kinetics, with criteria such as maximal mouth opening, rachis articular range, articular noise presence or not.

- Patient's pain with indicators such as muscle pressure pain threshold, and self-evaluation pain on visual analog scales or numeric scales.

\section{Study design}

Randomized controlled trials, randomized controlled trials metaanalysis, cohorts studies could be integrated in the summary, only if they don't show major bias, interfering with the data analysis. The studies with less than 20 subjects samples are excluded because of the weak generalization possibilities of such results to a population.

\section{Results}

\section{Selectionned Studies}

After sorting through 791 studies, eleven were selected. 8 are crosssectional cohort studies and 3 are comparative randomized trial studies published between 2010 and 2016 (Figure1).

\section{Bias assessment}

The randomized trial bias were measured using the Risk of bias of Chochrane and the Pedro Score as well [7-9]. The cohort studies bias was evaluated with the Newcastle-Ottawa scale [10].

\section{Samples}

Of the selected studies, six contain a sample of 100 subjects or more [11-16]. Seven studies are mixed sex samples, whereas the others concern an exclusively female sample [11-21]. At least six of the eleven studies had those following items included as criteria of patients:

- The jaw pain was evaluated to be at least $3 / 10$ on the visual numeric scale $[11-13,15,20,21]$.

- The pain duration must be of a minimum of three months [11$15,17,18,21]$.

- The myogenic TMD diagnosis is based on criteria defined by Dworkin and LeResche [2,11-21].
- The pain in the masticatory muscles must be bilateral [11,13,17,19-21].

Other inclusion criteria are listed in smaller proportions, namely, pain in the jaw for at least six months, cervical pain for more than 3 months, and also disabilities related to cervical according to the Neck disability index [17,19,20-22].

The exclusion criteria include musculoskeletal pathologies, temporomandibular surgeries, inflammatory, neurologic, or mental pathologies.

\section{Evaluation criteria}

Six cohorts and one randomized trial are evaluated, the evaluation criteria are:

- spontaneous pain intensity in the jaw [11-16,18,21]

- disability related to the jaw [11-16,18]

- disability related to cervical [11-16]

Other parameters can be analyzed by certain studies such as the pressure pain threshold, neuromuscular parameters (force, endurance, resting electromyographic activities), maximum oral opening, postural cephalic and cervical angles, pain span on the body surface, sympathetic parameters, mental traits, and sub-occipital or lumbar range of motion [12-21].

\section{Randomized trials: interventions and results}

Maluf [18] compared the effects of stretching anterior and posterior chains to analytic stretching of cervico-facial regions and of the upper limbs, combined with preliminary cervical pumping [18]. In 2013, La Touche et al. [21] noticed the effects of antero-posterior mobilization of the upper cervical rachis and compared the data to a placebo group. Rodriguez-Blanco [19] appreciated the effect of a sub-occipital myofacial inhibition technique combined to hamstring stretching and longitudinal masseter massage. At last, chain stretching or cervical analytics combined to upper cervical articulation mobilization seems to improve muscular TMD associated symptoms $[18,21]$. The suboccipital myofacial inhibition technique does not improve pain sensitivity, nor maximum oral aperture in immediate post intervention evaluation [19] (Figure 2).

\section{Cross cohort study: description and results}

From the muscular point of view, it appears (thanks to the electromyographic study) that an endurance decrease of $25 \%$ of the maximal force on the cervical flexors on subjects with a mixed TMD, but there is no difference in terms of intensity or electromyographic activity when compared to healthy subjects $[12,15]$. Signs of tiredness are identified on the cervical extensors on the patients with TMD [14]. The correlation between temporo-mandibular and cervical dysfunction is proven in patients with mixed or myogenic TMD $[11,16]$.

Analyzing morpho-static parameters reveals an increase of the eye-tragus-horizontal angle, correlated to the increase of disabilities related to the TMA (temporomandibular articulation), but, only in subjects with myogenic TMD [13]. This also underlines, an increase of the maximal mouth opening without pain, and an increase of the pain sensitivity while voluntary protrusion [20].

The pain sensitivity is increased in patients with cervicalgia in the trigemini zone, but also on extra-trigeminal zones for subjects with cervicalgia combined with myogenic TMD. The pain span is correlated to mental anxiety traits [17]. (Figure 3) 


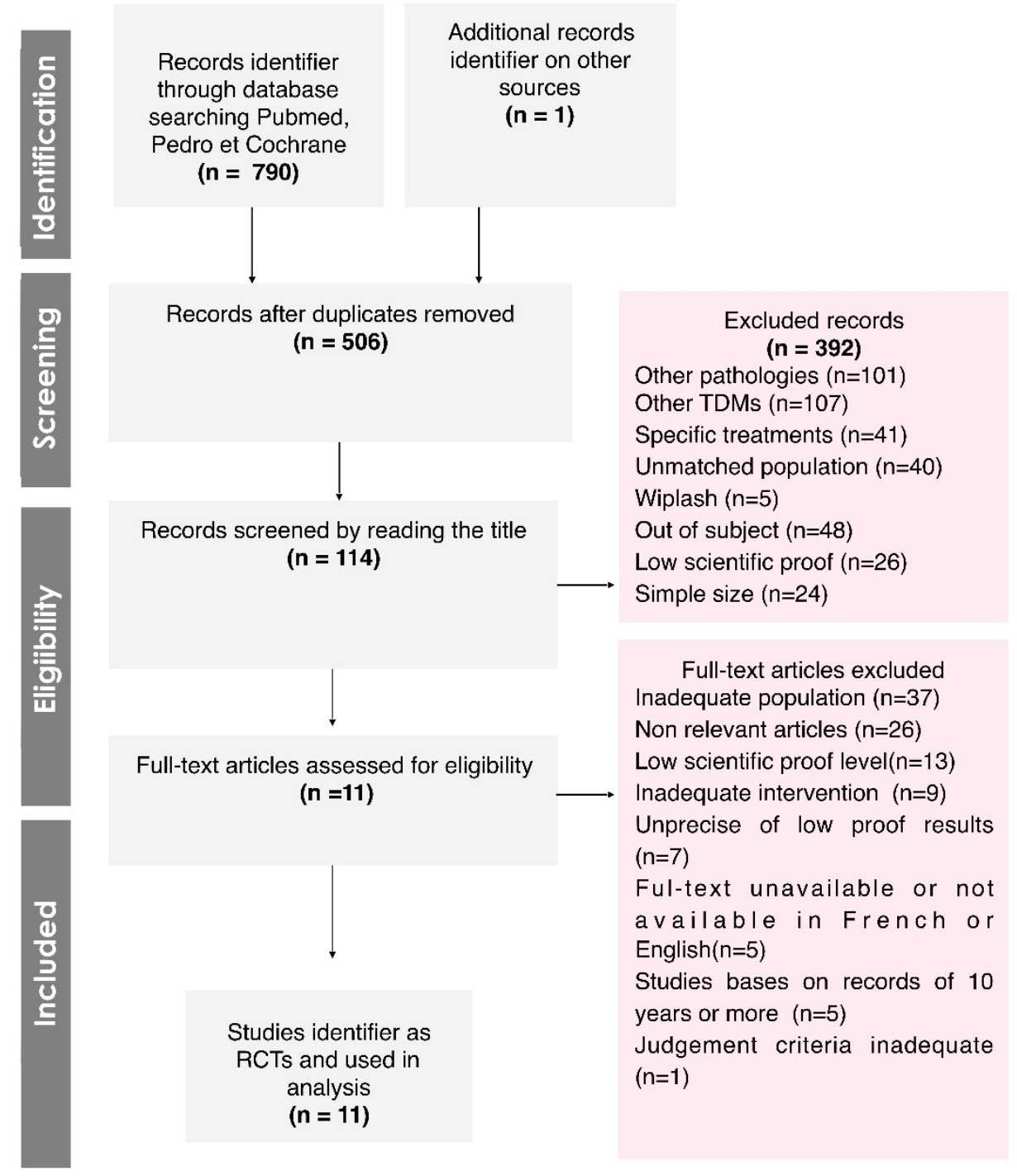

Figure 1. Flow diagram: identification, screening and selection of systematic reviews

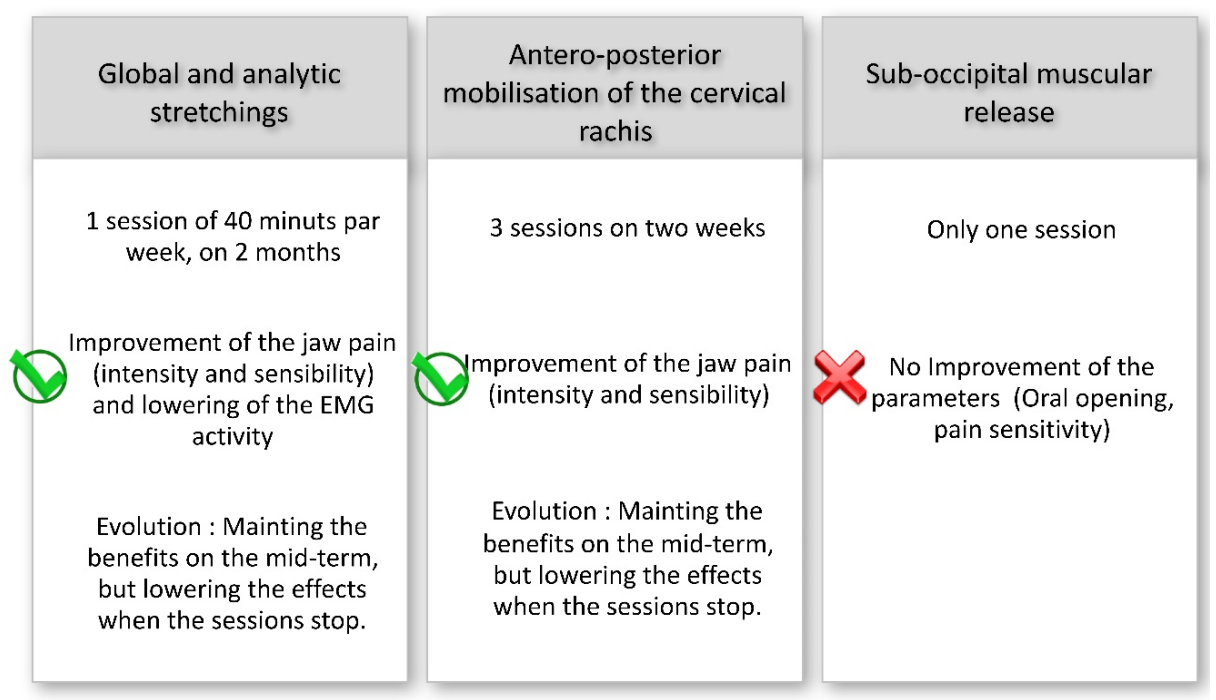

Figure 2. Synthesis: report on results of the randomised studies 


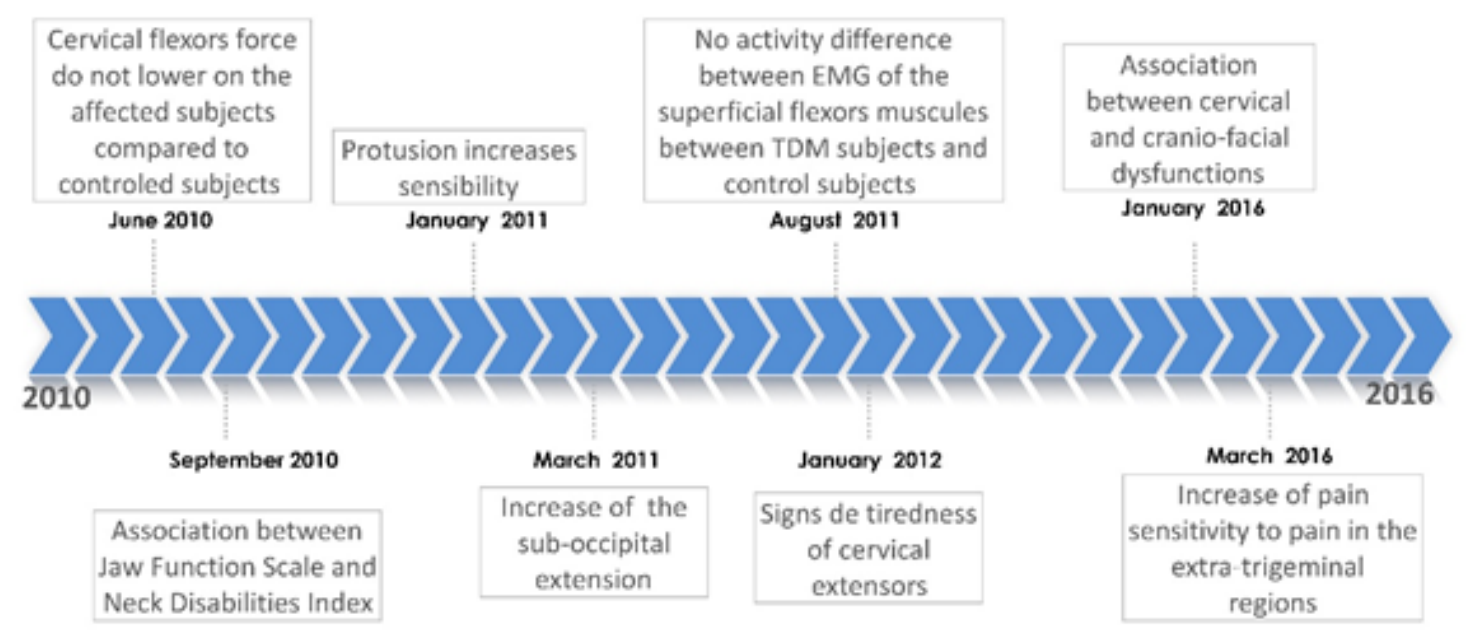

Figure 3. Synthesis: report on results of the cohort studies

\section{Discussion}

According to the EMG activity, patients with myogenic TMD do not present significant signs of cervical flexors alteration in terms of intensity, force and endurance [12]. A tendency to a non significant increase of the values in patients with TMD still suggest a superficial muscle hyper-activity to compensate a weakness of the deep muscles [15]. Moreover, signs of fatigue of cervical extensors are also detected by EMG [14]. We understand that lowering anterior and posterior muscular capabilities can lead to a forward collapse of the cervical curve, because these muscles play a part in the built station of the cervical rachis. Although, a reinforcement program recently showed an efficiency in relieving facial myalgia [24].

The eye-tragus horizontal angle increase suggest an increase of the sub-occipital extension [13]. We can assume that forwarding the lower and medium cervical rachis induce a compensatory hyper-extension of the high cervical rachis to maintain the eyesight horizontality [23]. The correlation between the increase of this angle and the incapability linked to the TMA in subjects with facial myalgia suggest a direct link between TMA dysfunctions and the increase in the upper cervical extension [13].

However, the clinical relevance of this increase is weak $\left(3^{\circ}\right)$ but could reveal a higher relevance if initials inclusion criteria were revealing of a more serious damage [13]. This biomechanic link is confirmed by showing that women with TMD have a forward head posture according to the tragus-C7-Horizontal angle when compared to healthy subjects [25]. Besides, maintaining the protrusion position lowers the pain sensitivity level in the trigeminal region, maximizes the masticatory reaction by neuromuscular spindles tension and creates a recoil of the condyle compared to the skull position $[20,26]$. This mechanics initiated the release and the maintain of pain conveyed by the auriculo-temporal nerve V3. If we consider the hyoid bone as a mandibular anchorage point to the scapular belt, we understand that manducators muscles must always adapt between rachis contraints and caudal fix point. (Figure 4)

Beyond the oro-facial pain, the forward head posture can lead to cervical pain by stimulating soft tissues on the column and by exiting nociceptive fibers of the cervical plexus (at the caudal core level through mandibular nerve anastomosis with the cervical plexus). The study on patient with cervicalgia underlines an increase of the sensitivity to the temporomandibular pain on patients without TMD and extra-trigeminal on patient with facial myalgia [17]. This data recall a remodeling of central pain regulation systems leading to a general sensibilization. Analyzing neurologic parameters, beyond the trigeminal region and their treatment answer could build up an axis for a systematic study on patients with myogenic TMD. Early studies brought up a dysregulation of the autonomous nervous system, by pupillometry, on these patients and an association of systemic dysfunction to TMD on other ones $[27,28]$.

From a physical therapy point of view, post-stretching results must be nuanced because cervical pumping was done before each and every interventions [18]. In the Rodriguez' study, the results are borderline, but the evaluation of the effects have been realized after a unique session and they are hardly comparable to other study results. ${ }^{19}$ However, the relation TMD-neurologic modulation is re-enforced by developing hypo-algesic effects after having applied physical therapy techniques away from TMA $[18,21]$. Thus, the pain sensitivity corporal area and the maintain of benefits of various techniques applied at distance of the jaw underlines the involvement of cortical systems in regulation of pain in TMD.

\section{Study and research limits}

The studies predominantly determine bilateral pain as an inclusion criteria in patients, whereas temporomandibular myalgia can be only unilateral. Besides, some muscles were not studied such as lateral and medial pterigoid muscles, flexors and extensors deep muscles nor supra and infra hyoid muscles. On another note, knowing that the oral cavity participate in the respiratory function, it would be relevant to study ventilatory modes (buccal or nasal) of patients, to establish a link between rachis status, ventilatory function and TMD.

We can consider new area and lines of studies such as muscular parameters analysis for deep cervical flexors, study of muscular reenforcement programs on deep flexors and cervical extensors, and also ventilatory mode evaluation and tongue positioning.

\section{Conclusion}

Synthesized data of the review underline a fatigability of extensors cervical muscles, a forward head posture and a sub-occipital hyperextension, creating constraints on the manducatory muscles. As the neurological field is concerned, subjects with myogenic temporomandibular disorders show chronic pain on the craniofacial field but also a greater pain sensitivity to the rest of the body. 

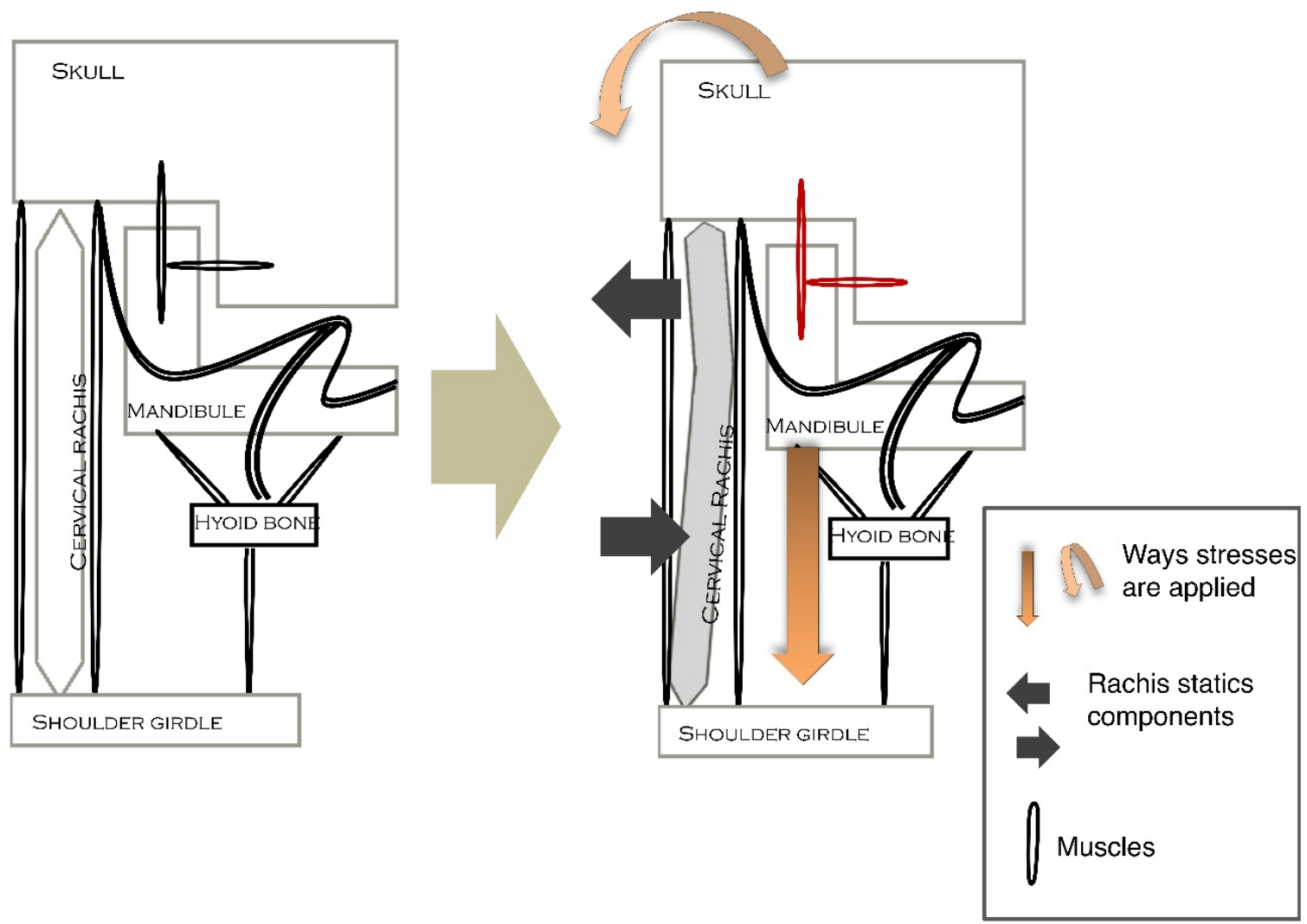

Figure 4. Improved Brodie-Ackerman's graphic

These elements put forward the hypothesis of pain cortical systemic remodeling. Thus, a nociceptive stimulation excess could lead to a re organization of supra-spinal systems modulating pain. From a kinesitherapic point of view, antero-posterior mobilization of high cervical rachis and repetitive global stretching or cervico-facial analytics seem to reduce symptoms, and their efficiency could increase in parallel to the frequency and number of session.

For now, it is relevant to extend this results and the kinesitherapic treatment of TMD beyond one articulation. Complementary studies are necessary to understand better physiolopathology of TMD and really show the effects of global, distal and postural kinesitherapic techniques.

\section{References}

1. National Institute of Dental and Craniofacial Research (2018) Prevalence of TMJD and Its Signs and Symptoms. National Institute of Dental and Craniofacial Research.

2. Dworkin SF, LeResche L (1992) Research diagnostic criteria for temporomandibular disorders: review, criteria, examinations and specifications, critique. J Craniomandib Disord 6: 301-355. [Crossref]

3. Schiffman E, Ohrbach RE, Truelove J, Look J, Anderson G, et al. (2014) Diagnosis Criteria for TemporoMandibular Disorders (DC/TDM) for Clinical and Research Applications: Recommendations of the International RDC/TDM Consortium Network and Orofacial Pain Specifial Interest Group. J Oral Facial Pain 28: 6-27. [Crossref]

4. Wiesinger B, Malker H, Englund E, Wänman A (2009) Does a dose-response relation exist between spinal pain and temporomandibular disorders. BMC Musculoskelet Disord 10: 28. [Crossref]

5. Calixtre LB, Moreira RFC, Franchini GH, Alburquerque-Sendín F, Oliveira AB, et al. (2015) Manual therapy for the management of pain and limited range of motion in subjects with signs ans symptoms of temporomandibular disorder: a systematic review of randomised controlled trials. J Oral Rehabil 42: 847-61. [Crossref]

6. Geddal M (2015) PRISMA guidelines for writing and reading of systematic reviews and meta analysis. Kine la Rev 15: 39-44
7. Higgins JPT, Green S (2008) Cochrane Handbook for Systematic Reviews of Intervention. Chichester (UK): The Cochrane Collaboration and John Wiley \& Sons Ltd 187-235.

8. Maher CG, Sherrington C, Herbert RD, Moseley AM, Elkins M (2003) Reliability of the PEDro scale for rating quality of randomized controlled trials. Phys Ther 83: 713721. [Crossref]

9. Macedo LG, Elkins MR, Maher CG, Moseley AM, Herbert RD, et al. (2010) There was evidence of convergent and construct validity of Physiotherapy Evidence Database quality scale for physiotherapy trials. J Clinical Epidemiol 63: 920-925. [Crossref]

10. Zeng X, Zhang Y, Kwong JS, Zhang C, Li S, Sun F, et al. (2015) The methodological quality assessment tools for pre-clinical and clinical studies, systematic review and meta-analysis, and clinical practice guideline: a systematic review. Int $J$ Evid Based Health 8: 2-10. [Crossref]

11. Olivo SA, Fuentes J, Major PW, Warren S, Thie NM, et al. (2010) The association between neck disability and jaw disability. J Oral Rehabil 37: 670-679. [Crossref]

12. Armijo-Olivo S, Fuentes JP, Da Costa BR, Major PW, Warren S, et al. (2010) Reduced endurance of the cervical flexor muscles in patients with concurrent temporomandibular disorders and neck disability. Man Ther 15: 586-592. [Crossref]

13. Armijo-Olivo S, Rappoport K, Fuentes J, Gadotti IC, Major PW, et al. (2011) Head and cervical posture in patients with temporomandibular disorders. J Orofac Pain 25: 199-209. [Crossref]

14. Armijo-Olivo S, Silvestre RA, Fuentes JP, da Costa BR, Major PW, et al. (2012) Patients with temporomandibular disorders have increased fatigability of the cervical extensor muscles. Clin J Pain 28: 55-64. [Crossref]

15. Armijo-Olivo S, Silvestre R, Fuentes J, da Costa BR, Gadotti IC, et al. (2011) Electromyographic activity of the cervical flexor muscles in patients with temporomandibular disorders while performing the craniocervical flexion test: a crosssectional study. Phys Ther 91: 1184-1197. [Crossref]

16. Gil-Martínez A, Grande-Alonso M, López-de-Uralde-Villanueva I, López-López A, Fernández-Carnero J, et al. (2016) Chronic Temporomandibular Disorders: disability, pain intensity and fear of movement. J Headache Pain 17: 103. [Crossref] 
17. Muñoz-García D, López-de-Uralde-Villanueva I, Beltran-Alacreu H, La Touche R, Fernández-Carnero J (2016) Patients with concomitant chronic neck pain and myofascial pain in masticatory muscles have more widespread pain and distal hyperalgesia than patients with only chronic neck pain. Pain Med 18: 526-537. [Crossref]

18. Maluf SA, Moreno BG, Crivello O, Cabral CM, Bortolotti G, et al. (2010) Global postural reeducation and static stretching exercises in the treatment of myogenic temporomandibular disorders: a randomized study. J Manipulative Physiol Ther 33: 500-507. [Crossref]

19. Rodriguez-Blanco C, Cocera-Morata FM, Heredia-Rizo AM, Ricard F, AlmazánCampos G, et al. (2015) Immediate effects of combining local techniques in the craniomandibular area and hamstring muscle stretching in subjects with temporomandibular disorders: a randomized controlled study. J Altern Complement 21: 451-459. [Crossref]

20. La Touche R, París-Alemany A, Von Piekartz H, Mannheimer JS, Fernández-Carnero $\mathrm{J}$, et al. (2011) The influence of cranio-cervical posture on maximal mouth opening and pressure pain threshold in patients with myofascial temporomandibular pain disorders. Clin J Pain 27: 48-55. [Crossref]

21. La Touche R, Mannheimer JF, Angulo-Diaz-Parreno S, París-Alemany A, Bishop MD, et al. (2013) Does mobilization of the upper cervical spine affect pain sensitivity and autonomic nervous system function in patients with cervico craniofacial pain. Clin $J$ Pain 29: 205-215. [Crossref]
22. Vernon H, Mior S (1991) The Neck Disability Index: a study of reliability and validity. J Manipulative Physiol Ther 14: 409-415. [Crossref]

23. Péninou G, Colné P (2018) Standing Posture, Fonctional biomechanic: from analysis to diagnosis. Issy-Les-Moulineaux: Elsevier-Masson.

24. Calixtre LB, Oliveira AB, De Sena Rosa LR, Armijo-Olivo S, Visscher CM, et al (2018) Effectiveness of mobilisation of the upper cervical region and craniocervical flexor training on orofacial pain, mandibular function and headache in women with TMD. A randomised, controlled trial. J Oral Rehabil 1-11. [Crossref]

25. Uritani PT, Kawakami T, Inoue T, Kirita T (2014) Characteristics of upper quadrant posture of young women with temporomandibular disorders. J Phys Ther Sci 26: 14691472. [Crossref]

26. Ohmure H, Miyawaki S, Nagata J, Ikeda K, Yamasaki K, et al. (2008) Influence of forward head posture on condylar position. J Oral Rehabil 35: 795-800. [Crossref]

27. Monaco A, Cattaneo R, Mesin L, Ortu E, Giannoni M, et al. (2015) Dysregulation of the descending pain system in temporomandibular disorders revealed by low-frequency sensory transcutaneous electrical nerve stimulation: a pupillometric study. Plos one 10 1-15. [Crossref]

28. Chen H, Nackley A, Miller V, Diatchenko L, Maixner W (2013) Multisystem dysregulation in painful temporomandibular disorders. J Pain 14: 983-996. [Crossref]

Copyright: $\odot 2019$ Aguila M. This is an open-access article distributed under the terms of the Creative Commons Attribution License, which permits unrestricted use, distribution, and reproduction in any medium, provided the original author and source are credited. 